\title{
Code Switching and Mixed Language Genesis in Tiwi
}

\author{
JUSTIN SPENCE \\ University of California, Davis
}

\section{Introduction}

A central issue in the study of mixed languages is the nature of their relationship to other language contact phenomena. Some scholars, notably Bakker (2003), have adopted the position that mixed languages are the result of autonomous processes of language mixing which operate independently of borrowing and code switching. However, McConvell and Meakins (2005) argue for the opposite view, demonstrating that the mixed language Gurindji Kriol has most plausibly arisen from grammaticization of pervasive code switching in a multilingual community. Building on this work, McConvell (2008) develops a "centre of gravity" model of mixed language genesis whereby some grammatical subsystems of a language are more robust than others and less likely to undergo replacement by morphemes from another language. A head-marking language will tend to retain its verbal subsystem in code-switched utterances, whereas a dependent-marking language will tend to retain its nominal subsystem. These patterns can be gramm aticized, leading to the emergence of so-called "Noun-Verb" (N-V) mixed languages with different sources for their nominal and verbal grammatical systems. This is contra Bakker, who maintains that typological considerations play very different roles in code switching and mixed language genesis (2003:130-132).

McConvell (2008) develops the center of gravity model most convincingly in light of data from mixed languages of northern Australia, noting that patterns of code switching for unmixed varieties would provide crucial evidence for or against his theory. However, he also acknowledges that only "limited data" on code switching is currently available for many of these languages. The present study is an attempt to shore up this empirical gap for one of McConvell's test cases. Data from the transcript of a public meeting are used to examine patterns of code switching in Tiwi, a head-marking polysynthetic language of northern Australia where an N-V mixed language has emerged among younger speakers (Lee 1987, McConvell 2008). McConvell's theory predicts that code switching behavior should reflect the same center of gravity principles as found in the 


\section{Justin Spence}

resulting mixed language. In particular, a head-marking language like Tiwi should most commonly provide the verbal part of code-switched utterances. Although the corpus used here is too small to draw definitive conclusions, the data do not support the supposed connections between morphological typology, code switching, and mixed language genesis. Reasonable interpretations of the data show no preference for code switching that retains Tiwi's verbal subsystem, as predicted by McConvell's center of gravity model.

The paper is structured as follows. Section 1 provides a more detailed overview of McConvell's theory and the arguments he develops to support it. Section 2 summarizes the Tiwi language situation and the data used in the present study. Section 3 considers certain analytical problems the data present - especially distinguishing code switching from borrowing and the use of a mixed language and the solutions adopted to deal with them. Section 4 presents the main results of the study and considers the extent to which they are consistent with the predictions of the center of gravity model. Section 5 discusses the theoretical significance of the results.

\section{Code Switching and Grammatical Centers of Gravity}

McConvell's center of gravity theory originates in observations about Gurindji Kriol (McConvell and Meakins 2005). This mixed language has developed only recently, in parallel with McConvell's documentation of language use in Gurindji communities since the 1970s. It combines elements of the Pama-Nyungan language Gurindji and Kriol, an English-lexified creole spoken across much of northern Australia. An N-V mixed language, the nominal grammar is supplied by Gurindji and the verbal grammar by Kriol. This is illustrated in example (1), where the main verb inflected for continuative aspect is from Kriol but the noun phrases and case morphology are from Gurindji: ${ }^{1}$

\section{(1) Ngali plei-bat nyawa-ngka}

1SG.INCL play-CONT this-LOC

'You and me can play here.' (McConvell and Meakins 2005:11)

McConvell and Meakins argue that this state of affairs resulted from grammaticization of earlier code switching between traditional Gurindji and Kriol, as in example (2), where the tense morphology and main verb are drawn from Kriol:

\footnotetext{
${ }^{1}$ Some glosses have been modified slightly to conform to the Leipzig Glossing Rules (Comrie, Haspelmath, and Bickel 2008). Non-conforming glosses used in this paper include HAVING for the Gurindji proprietive suffix, CONT for continuative aspect, and EMPH for the Tiwi emphatic prefix.
} 


\section{Code Switching and Mixed Language Genesis in Tiwi}

\section{(2) ail av-im kungulu-yawung \\ I'll have-TR blood-HAVING \\ 'I'll have the bloody meat.' (McConvell and Meakins 2005:18)}

Their analysis of data from the 1970 s showed that $60 \%$ of the clauses with code switching had Kriol as the Matrix Language (in the sense of Myers-Scotton), whereas only $28 \%$ had Gurindji as the Matrix Language. ${ }^{2}$ They suggest that the contemporary mixed language arose through grammaticization of the code switching patterns of the previous generation. Their argument is essentially one of plausibility: there are simply too many similarities between the code switching patterns in the 1970s and the grammatical split in the contemporary mixed language for other explanations to be likely.

McConvell's (2008) center of gravity theory addresses the question of why some languages in mixed language genesis contribute their nominal systems (like Gurindji in the development of Gurindji Kriol), while others contribute their verbal systems (like Cree in the development of Michif). McConvell suggests that a language can open up to 'turnover,' or replacement or of its systemic grammatical elements with morphemes from a new language, initially via code switching but eventually by grammatical convention. ${ }^{3}$ Left unchecked, the end result of turnover is presumably language shift (if there is concurrent replacement of openclass lexical items), or perhaps a mixed language with a grammar-lexicon split like Media Lengua. If the process of turnover is interrupted, however, grammatical elements from both languages are retained. According to McConvell, at least some $\mathrm{N}-\mathrm{V}$ mixed languages are the result of incomplete turnover, the crystallization of code switching patterns before all of a language's system morphemes have been replaced.

The key claim of the center of gravity theory is that turnover is not carried out willy-nilly. Rather, morphemes belonging to weak or less salient subsystems of the grammar are subject to replacement relatively early on. Strong subsystems those closer to the language's grammatical center of gravity - are affected later. According to this model, which subsystems resist replacement is determined by the head-marking versus dependent-marking typological parameter (Nichols 1986). In a dependent-marking language like Gurindji, the nominal case marking system is the center of gravity so verbal categories like tense, aspect, and mood are the elements most likely to be drawn from another source. In head-marking languages, by contrast, the verbal grammar is the center of gravity and will be retained, while the nominal system is subject to replacement. The outcome in both cases is a mixed language with a split between the nominal and verbal grammati-

\footnotetext{
${ }^{2}$ The remaining $12 \%$ were ambiguous with respect to matrix language.

${ }^{3}$ The distinction between the endogenous or 'old'language of a community versus an exogenous 'new' language is crucial: it is the center of gravity of the old language that resists replacement.
} 


\section{Justin Spence}

cal systems, but in one case the endogenous nominal system is retained, in the other the endogenous verbal system. McConvell's theory is appealing first of all because it provides a straightforward mechanism (code switching) for the development of mixed languages, and also because it invokes a reasonably wellunderstood structural-typological parameter to predict which language contributes which part of the grammar in $\mathrm{N}-\mathrm{V}$ mixed language genesis.

\section{Language Background and Data Source}

\subsection{Traditional and Modern Tiwi}

McConvell (2008) compares the transition from Gurindji to Gurindji Kriol with the case of Tiwi, a language isolate spoken on Melville and Bathurst Islands, situated $65 \mathrm{~km}$ north of Darwin off the coast of mainland Australia. Over the course of the $20^{\text {th }}$ century, Tiwi-speaking people had extensive contact with Australian English and regional English-lexified contact languages. ${ }^{4}$ Most Tiwi people developed some degree of proficiency in English, many through the mission school located at present-day Nguiu. During this period there does not seem to have been a policy of actively discouraging the use of Tiwi (Lee 1987:327), and Osborne (1974:3-4) reported as many as 1400 first-language Tiwi speakers. Nonetheless, by the late $20^{\text {th }}$ century the seeds of Tiwi endangerment had been sown: Osborne noted a decline in proficiency in younger generations and a threat from increased use of English in a number of official domains.

Lee (1987) describes an emergent mixed language she calls Modern Tiwi (MT) that has "amalgamated into a new code" (p. 340) using elements from Traditional Tiwi (TT), Pidgin English, and Standard Australian English. ${ }^{5}$ While the verbal system of MT has undergone major modifications from the TT system (noun incorporation and object agreement having been lost), subject marking and aspect morphology remain largely intact. Moreover, one of the main changes in the verbal system has been the expansion of a construction in which an uninflected main verb is accompanied by a light verb inflected with TAM morphology (Lee 1987:16). Thus (3) in TT is replaced with (4) in MT, where the Kriol main

\footnotetext{
${ }^{4}$ Lee calls the local English contact language 'Pidgin English' and treats it as a style of a 'Tiwi English' (TE) code; she is uncertain about its relationship to other contact varieties of English/Kriol spoken in northern Australia (1987:16-17). I will sidestep this issue below, generally referring to any language whose lexicon is derived primarily from English as 'English,' whether or not it may in fact be an English-lexified contact language.

${ }^{5}$ The situation is in fact much more complex than this, with four partially overlapping codes at play in the community: TT, MT, Tiwi English, and Standard Australian English, with additional stylistic and developmental gradations as well. The boundaries between the codes are quite fluid, making identification of code switching challenging. This problem is discussed in more detail in section 3 below.
} 


\section{Code Switching and Mixed Language Genesis in Tiwi}

verb kilim occurs with the Traditional Tiwi light verb jimi (McConvell 2008:199):

(3) yi-pirni

3SG:3SG-hit

'She hit him.' (TT)

(4) kilim ji-mi arra

hit 3SG-did 3SG

'She hit him.' (MT)

The upshot is that relexification of Tiwi verbs with English-derived forms retains Tiwi TAM marking, i.e., they have preserved Tiwi's grammatical center of gravity. ${ }^{6}$

The comparison between Modern Tiwi and Gurindji Kriol is especially apt since the history of language contact in the two cases is roughly similar: groups with similar cultural practices - according to Lee (1987:3), Tiwi culture is "fundamentally that of mainland Aborigines" - entered into contact with similar varieties of English (or English-lexified contact languages) during approximately the same period in history and under similar circumstances. While it would be a mistake to ignore entirely the micro-histories of contact in the two cases, it is nonetheless plausible that the main difference in the development of Gurindji Kriol versus Modern Tiwi is a typological one: Tiwi is a head-marking polysynthetic non-Pama-Nyungan language, whereas Gurindji is largely dependentmarking.

If center of gravity effects in N-V mixed language genesis are due to a typological constraint on code switching, the next question is whether Traditional Tiwi with code switching favors retention of Tiwi TAM marking as well. Although Lee (1987:337-342) includes discussion of code switching, she notes that there is "insufficient data to give many examples" (p. 341). Thus, while McConvell's claim that the Modern Tiwi light verb construction is the result of code switching patterns grammaticized before complete "turnover" to English is plausible, it is unclear whether patterns of language mixing found in MT are in fact attributable to patterns of code switching involving TT and English.

\footnotetext{
${ }^{6}$ McConvell does not discuss the MT nominal system, but his theory predicts that it should have undergone a relatively large amount of morphological replacement. Lee (1987:77-120, 317-318) outlines a number of changes in the nominal and pronominal systems which have shifted in the direction of English/Kriol, although this seems to be mainly at the semantic-functional level via simplifications to the TT system. Interestingly, Lee (1987:319) concludes that "there are relatively few changes in the structure of the Noun Phrases."
} 


\section{Justin Spence}

\subsection{Data}

Code switching data bearing on this issue are found in the transcript of a public meeting held at Nguiu in 1989 (Legislative Assembly of the Northern Territory 1996:335-362), a decade after Lee's fieldwork. The meeting was part of a process of community consultation undertaken by the Northern Territory government to discuss issues surrounding the possibility of becoming a full-fledged Australian state. The majority of the transcript is in English, with Aboriginal community members discussing matters with monolingual English-speaking government representatives. However, there are also stretches where three of the participants address their communities using a combination of English and Tiwi. It is clear from the rest of the transcript that all three speakers are fluent in a variety very close to Standard Australian English, so their use of Tiwi cannot be due to an inability to express themselves in English.

This transcript has the primary advantage of having a high degree of ecological validity. Although the speakers were aware that they were being recorded, their primary purpose was to communicate with members of their community, not to produce specimens of an authentic Tiwi language of yesteryear for linguists. Hence they were free to use whatever language they felt would best express what they wanted to say, including social-indexical meanings related via choice of linguistic code. The transcript can plausibly be taken as a sample of code switching behavior as it might commonly occur in the community, although this assumption will be problematized in section 5 below.

This data source has several disadvantages, however, two of which are especially vexing. First, the overall quantity of usable data is hardly overwhelming. There are only 76 clauses (or clause-like units) with both Tiwi and English elements, roughly half as many as McConvell and Meakins (2005) considered in their study of Gurindji Kriol. Of these, just over a mere half are clearly code switches, with most examples coming from a single speaker in an extended monologue relatively early in the meeting. Second, no information is provided about the speakers or the audience other than a list of names on the first page (although their genders are known from their titles). Thus, information is lacking that would permit inferences about which varieties of Tiwi and English the speakers and audience might be expected to know, or about the speakers' likely motivations for switching between Tiwi and English. Despite these flaws, some data is better than no data, and therefore this transcript can nonetheless be taken as evidence, albeit imperfect, bearing on the center of gravity theory. ${ }^{7}$

\footnotetext{
${ }^{7}$ Other problems with the data are less dire, but are mentioned for completeness. First, the transcriber is anonymous and thus the validity of the transcription might in some cases be suspect. In particular, it is unclear whether words rendered in English orthography may in fact be normalized tokens of an English-lexified contact variety. Regrettably, it has not been possible to obtain a
} 


\section{Code Switching and Mixed Language Genesis in Tiwi}

\section{$3 \quad$ Coding}

As noted in the introduction, a recurrent theme in the literature on language contact is the extent to which various phenomena interact and overlap with one another. This issue is no less problematic in analyzing the Tiwi code switching data. Lee describes the basic problem in the following passage:

Because of the number of loan words and structures from English or Pidgin English in MT, it is difficult to tell where mixing ends and internal switching begins... [T] here is no clear cut boundary between mixing and switching and hence no clear-cut boundary between MT and TE. (Lee 1987:340)

To evaluate the center of gravity theory's predictions, code switching must be distinguished from borrowing on the one hand and from single-code mixed language utterances on the other. It is therefore necessary to establish specific criteria for treating clauses with elements from multiple sources as code switching rather than something else and for identifying the Matrix Language of codeswitched utterances. This section makes explicit the decisions made in this regard.

\subsection{Code Switching vs. Borrowing}

Winford (2003:40-41) discusses two kinds of lexical borrowing that must be distinguished: highly conventionalized borrowing that does not vary much from speaker to speaker, and nonce borrowing, which may be unique to a particular situation or conversation. Winford points out that "nonce borrowing is similar to code switching, which varies according to convention as well," and that "borrowing in the strict sense and code mixing in bilingual situations must be viewed as potentially quite different phenomena, governed by separate dynamics" (2003:41). Teasing these two phenomena apart in the Tiwi data is crucial, since many of the potential cases of code switching involve single lexical items. In order to accurately assess the distribution of grammatical elements in clauses which contain code switching, it must be clear that they are really code switches rather than borrowings.

The following heuristics have been employed to help distinguish code switches from borrowings. When a clause has a shift in language corresponding to a multi-word constituent, it is counted as an embedded language island code switch, as in (5):

recording to check it against. Second, translations for the Tiwi sequences are given as a chunk at the end of each conversational turn (and sometimes not at all), so the alignment between the text and the translation is sometimes imperfect. 


\section{Justin Spence}

(5)
nimarra nyi-rra-ami
ngaji once every three
talk
2PL.NPST-EMPH-do there

or four months. Amongst yourselves.

'Meet together every three or four months amongst yourselves and talk about it.'

However, multi-word items which are arguably lexicalized single units, such as fishing license or write down, are not automatically counted as code switches but instead are treated in the same way as single-word switches.

Unsurprisingly, classifying single-word shifts is most problematic. Most have been coded as borrowings, since many are introduced concepts and lack equivalents in Traditional Tiwi (at least, none is given in Lee 1987 or Osborne 1974). Examples include committee, payday, airstrip, constitution, and parliament. Two others occur multiple times and with more than one speaker, even though TT equivalents can be found in Osborne (1974), suggesting they might be established borrowings as well: understand and meeting. Three words - properly (often in combination with understand), come back, and look - can be considered borrowings because they occur multiple times in the Traditional Tiwi texts recorded by Osborne (1974), and thus were already an established part of the language as spoken by elders in the early 1970 s. $^{8}$ According to these criteria the following is considered a Tiwi sentence with two borrowed words:

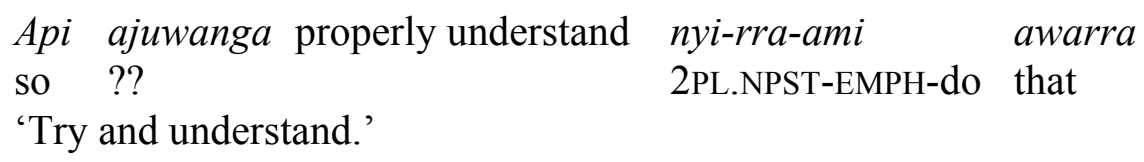

'Try and understand.'

Treating most single-word shifts to English as borrowings rather than code switches excludes from consideration at least five instances of the Tiwi light verb construction exemplified in (4) above. This deflates the number of code switches with Tiwi as Matrix Language and hence is disadvantageous for the center of gravity theory. Therefore, the results presented in section 4 will also consider the consequences of an alternative coding in which some single-word elements are treated as code switches instead of borrowings.

\footnotetext{
${ }^{8}$ This ignores the possibility that the elderly speakers Osborne worked with might have been code switching (perhaps for his benefit), but this seems unlikely insofar as the vast majority of the English-derived vocabulary in those texts are single words - there are only four cases of multiword English sequences. Moreover, there is a fair degree of uniformity in the texts - many of the same English elements occur repeatedly, and thus appear to be established borrowings rather than nonce insertions.
} 


\section{Code Switching and Mixed Language Genesis in Tiwi}

\subsection{Code Switching vs. Mixed Language}

Another problematic issue is distinguishing code switching between Tiwi and English from the ordinary use of Modern Tiwi (a mixed language considered as a unitary code). This is due to the fuzzy boundaries separating Traditional Tiwi from Modern Tiwi on the one hand, and Modern Tiwi from Tiwi English on the other. Nonetheless, there is a fair amount of evidence that, on the whole, the Tiwi language found in the data is Traditional Tiwi, and hence that the sentences with elements from more than one language should be considered instances of code switching.

First, there are several alternational code switches in the corpus with entire clauses that are uniquely English or uniquely Tiwi, as in (7) and (8):

(7) You've got to be all taken there, about courts, how they elect government.

$\begin{array}{lll}\begin{array}{ll}\text { nimarra } & \text { wu-ri-mi }\end{array} \text { tuwawanga } & \text { ngini } \\ \text { talk } & \text { 3PL.NPST-COM-do again } & \text { if/when/because } \\ \text { nuwa } & \text { nyimpi-timarti awarra } \\ \text { 2PL } & \text { 2PL.NPST-want that } \\ \text { 'They will talk to you about what you need to know. }{ }^{, 9}\end{array}$

Although an examination of the MT texts in Lee (1987:400-405) reveals some clauses with no trace of English elements at all, the reverse is not true: one does not find unbroken stretches of English-derived vocabulary. Thus, these interclausal switches, and some of the longer English sequences in sentences with intra-clausal code switches, suggest that the speakers are maintaining Tiwi and English as distinct codes to some extent.

Second, Lee (1987) identifies a number of phonological and grammatical criteria as being typical of TT but not MT. Individually, these would not be convincing, since many of them are tendential rather than categorical. However, all three speakers show clusters of these properties, including in sentences mixed with English, making the language seem much closer to TT than to MT. These properties are summarized as follows:

- Retention of post-alveolar consonants: $:^{10} \mathrm{TT}$ post-alveolar consonants tend to merge with the plain alveolar series in MT (Lee 1987:34-35). There is a preponderance of post-alveolar consonants in the speech of all three speakers in the data. Where Lee lists a difference between TT and MT (1987:367-92), the speakers consistently match the TT form. Examples include arnapa 'wait,'

\footnotetext{
${ }^{9}$ The translation is misaligned in the original transcript, so the one given here is approximate.

${ }^{10}$ Post-alveolars are transcribed as digraphs whose first member is $\left.\langle\mathrm{r}\rangle:\langle\mathrm{rt}\rangle,<\mathrm{rn}\right\rangle,<\mathrm{rl}>$.
} 


\section{Justin Spence}

yingarti 'lots,' and karluwu 'no, not.'

- Retention of word-initial /y/: Word-initial /y/ (transcribed $<$ ng $>$ ) is generally lost in MT (Lee 1987:39-41). There is a preponderance of word-initial velar nasals in the data, found with all three speakers. Examples include ngamamanta 'our friends,' ngini 'if,' and ngarra 'here.'

- Imperatives: Plural imperatives in TT are formed by prefixing a subject agreement marker nyi- to the singular imperative form of the verb (Osborne 1974:67, Lee 1987:187). Lee (1987:200) points out that these plural imperatives are exceedingly rare in MT, where the TT singular imperative is generally used for both singular and plural imperatives. The transcript contains numerous tokens of the plural imperative form.

- Object agreement: Object agreement prefixes do not occur in spontaneous MT, although younger people occasionally produce them in elicitation (Lee 1987:181-82). There are two certain cases of the object agreement prefixes in the data, and some other likely candidates as well.

- Locatives: TT has a set of locative words, glossed as 'here' and 'there,' which have a three-way contrast: close to speaker, close to hearer, and close to neither speaker nor hearer. In MT, this has collapsed to a simple two-way contrast. According to Lee (1987:129), the 'medial' (close to hearer) form ngaji is never found in MT, but there are several tokens in the data.

- Non-contracted forms: The lexicon in Lee (1987:367-392) includes many TT words that have undergone contraction in MT (apparently with some phonological regularities - Lee 1987:44-48). Contracted forms are sometimes optional in TT, but non-contracted forms are found only in TT. There are numerous examples of non-contracted forms in the data, including tuwawanga 'again' (MT tuwanga), awungarruwu 'there (distal)' (MT awarruwu), awungaji 'there (close to addressee)' (MT awaji), murrakupupuni 'country' (MT murrakupuni), nginingawula 'ours (emphatic)' (MT angawula).

- Lexical items: Many TT lexical items have been replaced by an Englishsourced word in MT (Lee 1987:367). There are several examples of these TT forms in the data, including -mamula 'to call' (MT kolim), punkaringini 'paper' (MT peypa) and -pawumi 'to cook' (MT kukim).

By contrast, very few features in the data would identify the language in the transcript as MT rather than TT. Some candidates include:

- One speaker produced three tokens of the MT reduced form $k a$ of the locative preposition kapi (but the full form more frequently).

- All three speakers use the future tense marker wiyi instead of nguyi, which Lee says is more typical of MT. However, a future tense marker wi (not nguyi) is included in Osborne's (1974) lexicon. Lee points out that "[e]ven for older speakers nguyi...is being replaced by wiyi" (1987:133), suggesting that it was 


\section{Code Switching and Mixed Language Genesis in Tiwi}

a change already far advanced in TT, and thus not diagnostic of MT per se.

- Two speakers use a form -mirampi 'children,' intermediate between TT -mamirampi and MT is -mirapi (Lee 1987:371), the latter with denasalization of the TT intervocalic stop.

- The light verb construction discussed by McConvell (2008; cf. ex. 4 above) is common in the data, generally with English-sourced non-inflecting verbs. However, other verbal constructions are also found, and the light verbs that do occur are in sentences containing other TT properties discussed above, notably several examples of the plural imperative construction. The same construction, often with English non-inflecting verbs, is reasonably common in Osborne's (1974) collection of TT texts. Thus, their occurrence in the meeting transcript might simply be the code switching precursor of the construction that becomes so prevalent in MT.

While a closer analysis of the transcript might reveal more unambiguously MT features, it seems that these are in the minority. All three speakers appear to have been using a mixture of two distinct codes: Traditional Tiwi and some variety of English. Thus, the data can be treated as switching between distinct codes rather than as a unitary mixed code.

\subsection{Finding the Matrix}

For each clause (or clause-like discourse unit) in the data coded as a plausible code switch, the Matrix Language was identified as either Tiwi or English. As noted by Winford (2003:141), there is no widely accepted way of doing this. To ensure some degree of comparability of results, the same criteria used by McConvell and Meakins (2005) for Gurindji Kriol were used: the language supplying a clause's TAM and agreement morphology is the Matrix Language. ${ }^{11}$ Thus, Tiwi is the ML in (9a) because it provides the future tense marker wiyi, whereas English is the ML in (9b) because it supplies the modal auxiliary might:

(9a) Everything ngawa wiyi look karrikamini left.

$1 \mathrm{PL} \quad$ FUT nothing

(9b) We might go back ngaji fifty or twenty, thirty years ago. there

'We might end up with nothing left like fifty, twenty, or thirty years.'

In (10), Tiwi is again the ML because it supplies the tense marker for the matrix

\footnotetext{
11 "As a rule of thumb, those clauses with Kriol tense-aspect-mood elements such as the past auxiliary 'bin' have Kriol ML and those with Gurindji auxiliaries, pronominal enclitics and TAM inflections on the verb have Gurindji ML” (McConvell and Meakins 2005:18-19).
} 


\section{Justin Spence}

clause:

(10) But before that comes in ngaji convention wiyi

'Before this happens we will have a convention.'

Clauses with an uninflected Kriol or English main verb only, as in (11), unless identified as an established borrowing are considered to have English as the ML, the rationale being that null marking is a property of the English TAM paradigm.

(11) kiyi ask them tuwawanga question then again

(untranslated in original: probably 'Then ask them questions again.')

Finally, some parts of the transcript are ambiguous with respect to Matrix Language. This is sometimes because there are possible TAM morphemes that haven't been identified, because the transcript is incomplete, or because a unit lacks a verb altogether. Some of this last group are not clauses at all, and hence may be irrelevant to the center of gravity theory, but others involve what could be analyzed as null copular constructions, as in (12):

(12) ngarra different awarra
this that
'They are different.'

Such ambiguous cases were coded separately, but as with borrowings alternative codings are considered in section 4.

\section{$4 \quad$ Results}

Applying the criteria discussed in section 3, the results of the study are summarized in the following table:

\begin{tabular}{|l|l|l|}
\cline { 2 - 3 } \multicolumn{1}{c|}{} & Code switch & Borrowing \\
\hline Tiwi ML & 12 & 25 \\
\hline English ML & 28 & 0 \\
\hline
\end{tabular}

The table is to be interpreted as follows. The column labeled "Code switch" identifies the number of clauses that were coded as having unambiguous cases of code switching. The column labeled "Borrowing" identifies clauses with material derived from both languages, but where the material was identified as a potential borrowing. There were in addition 11 clause-like units coded as having an ambiguous Matrix Language, not counted in the table. 


\section{Code Switching and Mixed Language Genesis in Tiwi}

Considering the unambiguous code switches alone, a clear majority of clauses $(28 / 40,70 \%)$ have English as the ML. This runs counter to the predictions of the center of gravity model: since Tiwi is a head-marking language, it is expected that most instances of code switching should retain Tiwi verbal system morphemes.

As noted above, it is likely that the number of code switches with Tiwi as Matrix Language is in fact somewhat higher: perhaps some of the 'borrowings' could be re-classified as 'nonce borrowings' and hence as some sort of code switch. This is almost certainly incorrect for most such cases, for the reasons outlined in section 3.1 - the borrowings are well-established in all varieties of Tiwi and are not possible loci for switching. Supposing as many as half of them were reclassified, however, Tiwi would still be the Matrix Language less than half the time (still setting aside the ambiguous cases): $(12+13) / 65$ or $38 \%$. If all 11 ambiguous cases were considered to have Tiwi as Matrix Language (if, for example, null copular clauses are considered to be paradigmatically a feature of Tiwi rather than English), clauses with Tiwi as Matrix language would still be in the minority: $(12+13+11) / 76$ or $47 \%$.

Perhaps an even higher proportion of the borrowings could be recoded to have Tiwi as Matrix Language, but even so it seems unlikely that the total would approach the $60 \%$ vs. $28 \%$ that McConvell and Meakins found for Kriol Gurindji code switching in the 1970s. Thus, even under a fairly generous coding of the data, no preference for Tiwi as Matrix Language emerges in Tiwi $\sim$ English code switching.

\section{Discussion and Conclusions}

While some ambiguities in the data remain, the patterns of Tiwi code switching examined here do not conform to the predictions of McConvell's center of gravity model. TAM marking in clauses with code switching is just as likely, if not more so, to be supplied by English (or Kriol) as it is by Traditional Tiwi. If this is representative of code switching input that led to the emergence of Modern Tiwi, there would be no reason to suspect that a mixed language retaining Tiwi verbal system morphology would emerge. This would seem to support Bakker's position that typological factors have very different effects in code switching versus mixed language genesis: if the head-marking/dependent-marking typology was at all relevant in the emergence of MT, it must have been by means of some mechanism other than code switching.

It could be argued that the code switching found in the public meeting transcript considered here is not, in fact, representative of code switching in the Tiwi community at large. Tiwi speakers might have used more English-framed clauses because they were in the presence of monolingual English speakers and were engaging with them in English to discuss political issues associated with AngloAustralian culture. This scenario was suggested by Lee (1987), who observed at community meetings that " $[\mathrm{t}]$ he English may have been mainly for the benefit of 


\section{Justin Spence}

the Europeans and mixed-race people present" (p. 334), and more generally that "[t]he presence of a European, even though not an active participant in the conversation, may influence the amount of English used" (p. 339). Such considerations could make data from this public meeting irrelevant to mixed language genesis.

Note, however, that this objection presupposes that the head-marking versus dependent-marking typological parameter does not in general determine patterns of code switching, which are instead highly dependent upon social context. Indeed, a more general finding of Lee's study of language use in Tiwi communities is that contextual factors such as setting (work, home, ceremonies, and so on) and the status of interlocutors play a crucial role in determining which linguistic code speakers are likely to use (1987:329-342). One of the codes Lee identified was a child-directed Tiwi Baby Talk, and it is there, she suggests, that salient features of MT must have originated (1987:355-356). From this perspective, the structural-typological constraint seems to play only a secondary role in code switching - and hence in mixed language genesis under McConvell's theory insofar as it is so easily overridden by speakers' knowledge of their social world. ${ }^{12}$ If head-marking vs. dependent-marking centers of gravity are at play in $\mathrm{N}-\mathrm{V}$ mixed language genesis, research moving forward must address the issue of why the typological parameter is active in some social contexts but inactive in others, especially child- vs. adult-directed speech.

\section{Acknowledgments}

I would like to thank Lev Michael and participants in his Fall 2008 seminar on language contact at UC Berkeley for helpful comments on earlier versions of this research, as well as the audience at BLS 38 for their questions and insights.

\section{References}

Bakker, Peter. 2003. Mixed Languages as Autonomous Systems. In P. Bakker \& Y. Matras, eds., The Mixed Language Debate: Theoretical and Empirical Advances, 107-150. Berlin: Mouton de Gruyter.

\footnotetext{
${ }^{12}$ Lee's account of Tiwi Baby Talk is discussed by O'Shannessy (2012) in her study of the emergent mixed language known as Light Warlpiri, spoken in the mainland Australian community of Lajamanu. Light Warlpiri is an $\mathrm{N}-\mathrm{V}$ mixed language with many of the same properties as Gurindji Kriol. O'Shannessy argues that in adult-to-adult code switching involving (traditional) Warlpiri and English, "there is not the verb-noun grammatical dichotomy seen in the codeswitching patterns of child-directed speech" (2012:327). That is, the patterns found in code switching vary depending primarily on interlocutor, not on the structural properties of the language involved.
} 


\section{Code Switching and Mixed Language Genesis in Tiwi}

Comrie, Bernard, Martin Haspelmath, and Balthasar Bickel. 2008. The Leipzig Glossing Rules: Conventions for Interlinear Morpheme-by-Morpheme Glosses. [http://www.eva.mpg.de/lingua/resources/glossing-rules.php]

Lee, Jennifer. 1987. Tiwi Today: A Study of Language Change in a Contact Situation. Pacific linguistics series C, no. 96. Canberra: Department of Linguistics, Research School of Pacific Studies, Australian National University.

Lee, Jennifer. 1988. Tiwi: A Language Struggling to Survive. Aboriginal Language Use in the Northern Territory: 5 Reports. Work Papers of SIL-AAIB series $\mathrm{B}$, vol 13: 75-96.

Legislative Assembly of the Northern Territory. 1996. Foundations for a Common Future: The Report on Paragraph 1(a) of the Committee's Terms of Reference on a Final Draft Constitution for the Northern Territory. Vol. 5, part B[1] - Hansard Transcripts of Public Hearings. [http://www.nt.gov.au/lant/parliamentarybusiness/committees/condev/reports/Vol5-B1.pdf]

McConvell, Patrick. 2008. Mixed Languages as Outcomes of Code Switching: Recent Examples from Australia and Their Implications. Journal of Language Contact, Thema 2: 187-212.

McConvell, Patrick and Felicity Meakins. 2005. Gurindji Kriol: A Mixed Language Emerges from Code-Switching. Australian Journal of Linguistics 25(1): 9-30.

Nichols, Johanna. 1986. Head-Marking and Dependent-Marking Grammar. Language 62(1): 56-119.

Osborne, C.R. 1974. The Tiwi Language. Canberra: AIAS.

O'Shannessy, Carmel. 2012. The Role of Code-Switched Input to Children in the Origin of a New Mixed Language. Linguistics 50(2): 305-340.

Winford, Donald. 2003. An Introduction to Contact Linguistics. Malden, MA: Blackwell. 


\section{Justin Spence}

Justin Spence

Native American Studies Department

University of California, Davis

2401 Hart Hall

One Shields Avenue

Davis, CA 95616

jspence@ucdavis.edu 